\title{
Complications of the Early Neonatal Period in Children from Mothers with Gestational Diabetes Mellitus
}

\author{
Agamurad A. Orazmuradov, $\mathrm{PhD}, \mathrm{ScD}^{1}$; Irina V. Bekbaeva ${ }^{1 *}$; Gayane A. Arakelyan ${ }^{1}$; \\ Anastasia V. Minaeva ${ }^{1}$; Anastasiya N. Akhmatova, $\mathrm{PhD}^{1}$; Khalid Haddad ${ }^{1}$; Zhasmina Z. \\ Suleymanova $^{1}$; Sergey I. Kyrtikov ${ }^{1}$; Nozimabonu M. Zokirova ${ }^{1}$; Aleksey A. Lukaev, PhD ${ }^{2}$

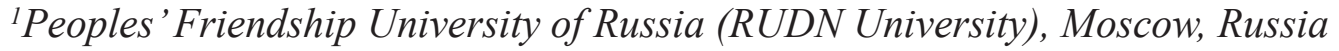 \\ ${ }^{2}$ Mytishchi City Clinical Hospital Mytishchi, Moscow Region, Russia
}

\begin{abstract}
Background: Changes in the course of gestational diabetes mellitus at the present stage determine the emergence of a certain spectrum of completely new problems associated with the health status of newborns from mothers with gestational diabetes mellitus. The aim of the study was to investigate early neonatal complications in newborns from mothers with gestational diabetes mellitus.

Methods and Results: The study included 404 pregnant women (gestational age of 37.0-41.0 weeks) with gestational diabetes mellitus. All patients with gestational diabetes mellitus were divided into 2 groups. Group 1 included 188 patients receiving insulin therapy; Group 2 included 216 patients receiving a well-balanced diet. The control group (Group 3) consisted of 68 pregnant women without disorders of carbohydrate metabolism. In Group 1, macrosomia occurred in 44(23.4\%) newborns, in Group 2 - in 48(22.0\%) newborns; in newborns from mothers of the control group, the frequency of macrosomia was only in $7.35 \%$ of newborns $(P=0.01)$. Morpho-functional immaturity of newborns had the highest frequency of occurrence, despite the fact that all children were born on time; 80(42.6\%) newborns from mothers of Group 1 and 77(35.6\%) newborns from mothers of Group 2 had signs of morpho-functional immaturity.

Conclusion: Diabetic fetopathy in newborns from mothers with gestational diabetes mellitus is manifested by morphofunctional immaturity of organs and systems developing in unfavorable hyperglycemic conditions. (International Journal of Biomedicine. 2021;11(4):414-417.)
\end{abstract}

Key Words: gestational diabetes mellitus $\bullet$ hypoglycemia $\bullet$ diabetic fetopathy $\bullet$ macrosomia

For citation: Orazmuradov AA, Bekbaeva IV, Arakelyan GA, Minaeva AV, Akhmatova AN, Haddad Kh; Suleymanova ZhZ, Kyrtikov SI, Zokirova NM, Lukaev AA. Complications of the Early Neonatal Period in Children from Mothers with Gestational Diabetes Mellitus. International Journal of Biomedicine. 2021;11(4):414-417. doi:10.21103/Article11(4) OA3

\section{Abbreviations}

GDM, gestational diabetes mellitus; CNS, central nervous system; DF, diabetic fetopathy; RDS, respiratory distress syndrome.

\section{Introduction}

Changes in the course of gestational diabetes mellitus (GDM) at the present stage determine the emergence of a certain spectrum of completely new problems associated with the health status of newborns from mothers with GDM. This change was influenced by, first,, the obesity pandemic and the prevalence of pregestational insulin resistance, which is responsible for the earlier onset of GDM; and, second, the emergence of clear, uniform diagnostic criteria adopted by major international medical associations.

The most common neonatal complication in GDM is diabetic fetopathy (DF). ${ }^{(1-4)}$ However, in the world literature, there are practically no data on its most significant manifestations - the main problems of the early neonatal period. The frequency of DF in the era of new, more accurate criteria for the diagnosis of GDM by IADPSG (International Association of Diabetes and Pregnancy Study Groups) has 
significantly decreased. ${ }^{(5,6)}$ Previously, prevailing severe forms of DF, accompanied by visceromegaly, severe damage to the central nervous system (CNS), and multiple organ failure, determined the high level of perinatal mortality in GDM. ${ }^{(3,7)}$ The introduction of strict, uniform diagnostic criteria and national hyperglycemia screening programs have positively influenced the levels of perinatal morbidity and mortality.

However, the problem of complications in newborns from mothers with GDM is not limited to the "traditional" symptom complexes of DF. According to modern data, the structure of DF is currently dominated by functional disorders caused by the immaturity of body systems formed against the background of existing pregestational disorders of carbohydrate and lipid metabolism..$^{(1,4,6,8)}$ These include neural tube defects, CNS depression, minimal heart defects, hepatic steatosis, and intestinal dysbiosis in newborns. . $^{(2,49)}$

The aim of the study was to investigate early neonatal complications in newborns from mothers with GDM.

\section{Materials and Methods}

The study included 404 pregnant women (gestational age of 37.0-41.0 weeks) with GDM and 68 without disorders of carbohydrate metabolism, who gave birth from the second quarter of 2018 to the third quarter of 2020 in the maternity ward of the City Clinical Hospital No. 29 named after N.E. Bauman. This was a prospective case-control study.

All patients with GDM were divided into 2 groups. Group 1 included 188 patients receiving insulin therapy; Group 2 included 216 patients receiving a well-balanced diet. The control group (Group 3) consisted of 68 pregnant women without disorders of carbohydrate metabolism.

The study was conducted in accordance with the ethical principles of the WMA Declaration of Helsinki (1964, ed. 2013) and was approved by the Ethics Committee of the RUDN University. Written informed consent was obtained from all participants.

Inclusion criteria were full-term pregnancy, cephalic presentation, and singleton pregnancy. Exclusion criteria were multiple pregnancy, premature birth, and breech presentation of the fetus. The diagnosis of GDM was based on the clinical recommendations of the $\mathrm{MH}$ of $\mathrm{RF}^{(8)}$

The condition of newborns was assessed in the first minutes of life, in the first day of life and in the early neonatal period. Assessment of the state of a newborn in the early neonatal period began with an examination in the delivery room by a neonatologist, and included: 1) measurement of anthropometric parameters (weight, height, head circumference, chest circumference); 2) the presence or absence of phenotypic signs of DF, such as macrosomia, pitting edema, disproportionate physique, morpho-functional immaturity, moonlike face, cardiomegaly, splenomegaly, hepatomegaly, hypertrichosis, hyperbilirubinemia, hypoglycemia, neonatal CNS depression, RDS; 3 ) assessment of the Apgar score (at 1 minute and 5 minutes after birth); 4) the need for respiratory support and its duration, the duration of hospital stay; 5) perinatal brain damage.

Macrosomia was defined as a birth weight greater than or equal to $4000 \mathrm{~g}$.
The criteria for morpho-functional immaturity included pronounced lanugo on the body, soft auricles, softened skull bones, a short neck, undescended testicles in the scrotum in boys, and uncovered labia minora with the labia majora in girls. The blood glucose concentration in newborns was measured 1 or more times a day, depending on the condition of the newborn, using a Glucometer "Accu-Chek Active New"(Switzerland) and visual test strips "Accu-Chek." Hypoglycemia was defined as blood glucose concentration $<2.6 \mathrm{mmol} / \mathrm{L}$ at any time after birth.

Statistical analysis was performed using the Statistica 8.0 software package (StatSoft Inc, USA). Baseline characteristics were summarized as frequencies and percentages for categorical variables and as means and standard error of the mean (SEM) for continuous variables. Multiple comparisons were performed with one-way ANOVA and Tukey's HSD Post-hoc Test. Group comparisons with respect to categorical variables are performed using the chisquare test or, alternatively, Fisher's exact test. A value of $P<0.05$ was considered statistically significant.

\section{Results}

The 1-minute and 5-minute Apgar scores in newborns from mothers of Groups 1 and 2 were moderately lower than in newborns from mothers of the control group. Consequently, newborns from women with GDM showed lower adaptive abilities in the first minutes after birth (Table 1).

Table 1.

The Apgar score in the study groups

\begin{tabular}{|c|c|c|}
\hline Groups & The 1-minute Apgar score & The 5-minute Apgar score \\
\hline $\begin{array}{c}\text { Group 1 } \\
(\mathrm{n}=188)\end{array}$ & $8.2 \pm 0.7$ & $8.8 \pm 0.7$ \\
\hline $\begin{array}{c}\text { Group 2 } \\
(\mathrm{n}=216)\end{array}$ & $8.4 \pm 0.6$ & $9.0 \pm 0.9$ \\
\hline $\begin{array}{c}\text { Group 3 } \\
(\mathrm{n}=68)\end{array}$ & $8.7 \pm 0.4$ & $9.4 \pm 0.5$ \\
\hline$P$-value & 0.9158 & 0.9267 \\
\hline
\end{tabular}

The average birth weight in newborns from women with GDM was moderately higher than in newborns from mothers of the control group. These data were due to the higher frequency of macrosomia in the GDM groups. Thus, in Group 1, macrosomia occurred in 44(23.4\%) newborns, in Group 2 - in 48(22.0\%) newborns. In newborns from mothers of the control group, the frequency of macrosomia was only in $7.35 \%$ of newborns $(P=0.01)$ (Table 2$)$.

In newborns from GDM mothers, complications such as hypoglycemia, symptoms of neonatal CNS depression, hepatomegaly, morpho-functional immaturity, and RDS were significantly more frequent (Table 3). Morpho-functional immaturity of newborns had the highest frequency of occurrence, despite the fact that all children were born on 
time; $80(42.6 \%)$ newborns from mothers of Group 1 and $77(35.6 \%)$ newborns from mothers of Group 2 had signs of morpho-functional immaturity. In second place, in terms of frequency of occurrence, was hepatomegaly, which occurred in 60(31.9\%) newborns from mothers of Group 1 and 44(20.3\%) newborns from mothers of Group 2. Approximately the same frequency was observed for such complications of the early neonatal period as hypoglycemia and neonatal CNS depression. RDS was the least common, accounting for $10.1 \%$ of newborns from mothers of Group 1 and $6.9 \%$ of newborns from mothers of Group 2.

Table 2.

Anthropometric indicators of newborns

\begin{tabular}{|c|c|c|}
\hline Groups & $\begin{array}{c}\text { Birth weight } \\
\text { M } \pm \text { SEM }\end{array}$ & $\begin{array}{c}\text { Macrosomia } \\
\mathrm{n}(\%)\end{array}$ \\
\hline $\begin{array}{c}\text { Group 1 } \\
(\mathrm{n}=188)\end{array}$ & $3624.9 \pm 588.9$ & $44(23.4 \%)$ \\
\hline $\begin{array}{c}\text { Group 2 } \\
(\mathrm{n}=216)\end{array}$ & $3627.9 \pm 542.0$ & $48(22.2 \%)$ \\
\hline $\begin{array}{c}\text { Group 3 } \\
(\mathrm{n}=68)\end{array}$ & $3463.8 \pm 354.2$ & $5(7.35)$ \\
\hline$P$-value & 0.9864 & 0.0138 \\
\hline
\end{tabular}

Table 3.

\section{Neonatal complications in newborns}

\begin{tabular}{|c|c|c|c|c|c|}
\hline Groups & $\begin{array}{c}\text { Hypogly- } \\
\text { cemia }\end{array}$ & $\begin{array}{c}\text { CNS } \\
\text { depression }\end{array}$ & $\begin{array}{c}\text { Hepato- } \\
\text { megaly }\end{array}$ & MFI & RDS \\
\hline $\begin{array}{l}\text { Group 1 } \\
(\mathrm{n}=188)\end{array}$ & $40(21.2 \%)$ & $55(29.3 \%)$ & $60(31.9 \%)$ & $80(42.6 \%)$ & $19(10.1 \%)$ \\
\hline $\begin{array}{l}\text { Group 2 } \\
(\mathrm{n}=216)\end{array}$ & $45(20.8 \%)$ & $45(20.8 \%)$ & $44(20.3 \%)$ & $77(35.6 \%)$ & $15(6.9 \%)$ \\
\hline $\begin{array}{c}\text { Group 3 } \\
(\mathrm{n}=68)\end{array}$ & $4(4.6 \%)$ & $3(4.4 \%)$ & $2(2.9 \%)$ & $4(5.8 \%)$ & 0 \\
\hline$P$-value & 0.0125 & 0.0001 & 0.0000 & 0.0000 & 0.0248 \\
\hline
\end{tabular}

MFI - Morpho-functional immaturity

Diabetic cardiomyopathy was significantly more common in children from mothers of Group 1 (Table 4). However, it should be noted that the incidence of this complication was quite low $-4.2 \%$. In addition, DF was significantly more common in newborns from women of Group 1, which confirms the fact that the course of insulintreated GDM was more severe.

Diabetic cardiomyopathy is one of the most severe manifestations of the uncompensated course of GDM in mothers. ${ }^{(3,10)}$ The data on the incidence of cardiomyopathy, according to the literature, vary significantly: from $6.7 \%$ to $43.0 \%$ of newborns from GDM mothers. ${ }^{(4-6,8,10)}$ Palmieri et al. ${ }^{(11)}$ revealed echo signs of cardiomyopathy in $50.8 \%$ of fetuses from mothers with untreated GDM already at 30 weeks of gestation. The introduction of more stringent IADPSG criteria for the diagnosis of GDM contributed to a decrease in the incidence of cardiomyopathy, as well as the rate of perinatal morbidity and mortality. According to Billionet et al., ${ }^{(9)}$ GDM is associated with a moderately increased risk of adverse perinatal outcomes, which is higher in insulin-treated GDM than in non-insulin-treated GDM for most outcomes.

Table 4.

Diabetic fetopathy and cardiomyopathy in newborns from GDM women

\begin{tabular}{|c|c|c|}
\hline Groups & Diabetic fetopathy & Diabetic cardiomyopathy \\
\hline $\begin{array}{c}\text { Group 1 } \\
(\mathrm{n}=188)\end{array}$ & $79(42.0 \%)$ & $8(4.2 \%)$ \\
\hline $\begin{array}{l}\text { Group 2 } \\
(\mathrm{n}=216)\end{array}$ & $56(25.9 \%)$ & 0 \\
\hline$P$-value & 0.0006 & 0.002 \\
\hline
\end{tabular}

\section{Conclusions}

The state of health of newborns from mothers with GDM is characterized by a high incidence of macrosomia and hepatomegaly, as well as hypoglycemia, neonatal CNS depression, and morpho-functional immaturity.

Diabetic cardiomyopathy, as a marker of insufficient glycemic compensation and a more severe course of the disease, was found in newborns from mothers with insulintreated GDM. However, the incidence of this complication was low.

Diabetic fetopathy in newborns from mothers with GDM is manifested by morpho-functional immaturity of organs and systems developing in unfavorable hyperglycemic conditions.

\section{Competing Interests} interests.

The authors declare that they have no competing

\section{Sources of Funding}

This paper has been supported by the RUDN University Strategic Academic Leadership Program

\section{References}

1. Babiyants AYa, Afonin AA. [Problems of perinatal lesions of the central nervous system in children born to women with diabetes]. Zhurnal Fundamental'noy Meditsiny i Biologii. 2017;(2):28-37. [Article in Russian].

"Corresponding author: Irina V. Bekbaeva, Peoples' Friendship University of Russia (RUDN University), Moscow, Russia.E-mail: iridescentgirl@yandex.ru 
2. Nikitina IL, Konoplya IS, Polyanskaya AA, Liskina AS, Popova PV. [Characterization of psychological and physical development in children of gestation diabetes pregnanciesc]. Meditsinskiy Sovet. 2017;(9):14-20. [Article in Russian].

3. Radzinsky VE, Botasheva TL, Papysheva OV. Obesity. Diabetes. Pregnancy. Versions and contraversions. Clinical practices. Perspectives. M: GEOTAR-Media, 2020. [In Russian].

4. Domanski G, Lange AE, Ittermann T, Allenberg H, Spoo RA, Zygmunt M, Heckmann M. Evaluation of neonatal and maternal morbidity in mothers with gestational diabetes: a population-based study. BMC Pregnancy Childbirth. 2018 Sep 10;18(1):367. doi: 10.1186/s12884-018-2005-9.

5. ACOG Practice Bulletin No. 190: Gestational Diabetes Mellitus. Obstet Gynecol. 2018 Feb;131(2):e49-e64. doi: 10.1097/AOG.0000000000002501.

6. Bogdanet D, Egan A, Reddin C, Kirwan B, Carmody L, Dunne F. ATLANTIC DIP: Despite insulin therapy in women with IADPSG diagnosed GDM, desired pregnancy outcomes are still not achieved. What are we missing? Diabetes Res Clin Pract. 2018 Feb;136:116-123. doi: 10.1016/j. diabres.2017.12.003.

7. Guo H, Zhang Y, Li P, Zhou P, Chen LM, Li SY.
Evaluating the effects of mobile health intervention on weight management, glycemic control and pregnancy outcomes in patients with gestational diabetes mellitus. J Endocrinol Invest. 2019 Jun;42(6):709-714. doi: 10.1007/s40618-0180975-0.

8. Gestational diabetes mellitus. Diagnostics, treatment, obstetric tactics, postpartum follow-up. Clinical guidelines. Russian Association of Endocrinologists. Russian Society of Obstetricians and Gynecologists. Moscow, 2020. [In Russian]. 9. Billionnet C, Mitanchez D, Weill A, Nizard J, Alla F, Hartemann A, Jacqueminet S. Gestational diabetes and adverse perinatal outcomes from 716,152 births in France in 2012. Diabetologia. 2017 Apr;60(4):636-644. doi: 10.1007/ s00125-017-4206-6.

10. Akhmetova ES, Lareva NV, Mudrov VA, Gergesova EE. [Features of pregnancy with gestational diabetes mellitus and prediction of diabetic fetopathy]. Journal of Obstetrics and Women's Diseases.2017;66(4):14-24. [Article in Russian]. 11. Palmieri CR, Simões MA, Silva JC, Santos AD, Silva MR, Ferreira B. Prevalence of Hypertrophic Cardiomyopathy in Fetuses of Mothers with Gestational Diabetes before Initiating Treatment. Rev Bras Ginecol Obstet. 2017 Jan;39(1):9-13. English. doi: 10.1055/s-0037-1598602. 